\title{
Effects of Resistance Training on Change-of-Direction Speed in Youth and Young Physically Active and Athletic Adults: A Systematic Review with Meta-Analysis
}

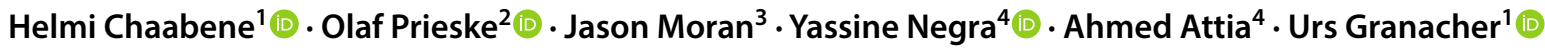

Published online: 25 May 2020

(c) The Author(s) 2020

\begin{abstract}
Background Change-of-direction $(\mathrm{CoD})$ speed is a physical fitness attribute in many field-based team and individual sports. To date, no systematic review with meta-analysis available has examined the effects of resistance training (RT) on CoD speed in youth and adults.

Objective To aggregate the effects of RT on CoD speed in youth and young physically active and athletic adults, and to identify the key RT programme variables for training prescription.

Data sources A systematic literature search was conducted with PubMed, Web of Science, and Google Scholar, with no date restrictions, up to October 2019, to identify studies related to the effects of RT on CoD speed.

Study Eligibility Criteria Only controlled studies with baseline and follow-up measures were included if they examined the effects of RT (i.e., muscle actions against external resistances) on CoD speed in healthy youth (8-18 years) and young physically active/athletic male or female adults (19-28 years).

Study Appraisal and Synthesis Methods A random-effects model was used to calculate weighted standardised mean differences (SMD) between intervention and control groups. In addition, an independent single training factor analysis (i.e., RT frequency, intensity, volume) was undertaken. Further, to verify if any RT variable moderated effects on CoD speed, a multivariate random-effects meta-regression was conducted. The methodological quality of the included studies was assessed using the physiotherapy evidence database (PEDro) scale.

Results Fifteen studies, comprising 19 experimental groups, were included. The methodological quality of the studies was acceptable with a median PEDro score of 6. There was a significant large effect size of RT on CoD speed across all studies $(\mathrm{SMD}=-0.82[-1.14$ to -0.49$])$. Subgroup analyses showed large effect sizes on CoD speed in males $(\mathrm{SMD}=-0.95)$ contrasting with moderate improvements in females $(\mathrm{SMD}=-0.60)$. There were large effect sizes on CoD speed in children $(\mathrm{SMD}=-1.28)$ and adolescents $(\mathrm{SMD}=-1.21)$ contrasting with moderate effects in adults $(\mathrm{SMD}=-0.63)$. There was a moderate effect in elite athletes $(\mathrm{SMD}=-0.69)$ contrasting with a large effect in subelite athletes $(\mathrm{SMD}=-0.86)$. Differences between subgroups were not statistically significant. Similar improvements were observed regarding the effects of independently computed training variables. In terms of RT frequency, our results indicated that two sessions per week induced large effects on $\mathrm{CoD}$ speed $(\mathrm{SMD}=-1.07)$ while programmes with three sessions resulted in moderate effects $(\mathrm{SMD}=-0.53)$. For total training intervention duration, we observed large effects for $\leq 8$ weeks $(\mathrm{SMD}=-0.81)$ and $>8$ weeks $(\mathrm{SMD}=-0.85)$. For single session duration, we found large effects for $\leq 30 \mathrm{~min}$ and $\geq 45 \mathrm{~min}$ (both $\mathrm{SMD}=-1.00$ ). In terms of number of training sessions, we identified large effects for $\leq 16$ sessions $(\mathrm{SMD}=-0.83)$ and $>16$ sessions $(\mathrm{SMD}=-0.81)$. For training intensity, we found moderate effects for light-to-moderate ( $\mathrm{SMD}=-0.76)$ and vigorous-to-near maximal intensities $(\mathrm{SMD}=-0.77)$. With regards to RT type, we observed large effects for free weights ( $\mathrm{SMD}=-0.99)$ and machinebased training $(\mathrm{SMD}=-0.80)$. For combined free weights and machine-based training, moderate effects were identified $(\mathrm{SMD}=-0.77)$. The meta-regression outcomes showed that none of the included training variables significantly predicted the effects of RT on CoD speed $\left(R^{2}=0.00\right)$.

Conclusions RT seems to be an effective means to improve CoD speed in youth and young physically active and athletic adults. Our findings indicate that the impact of RT on CoD speed may be more prominent in males than in females and in
\end{abstract}

Extended author information available on the last page of the article 
youth than in adults. Additionally, independently computed single factor analyses for different training variables showed that higher compared with lower RT intensities, frequencies, and volumes appear not to have an advantage on the magnitude of CoD speed improvements. In terms of RT type, similar improvements were observed following machine-based and free weights training.

\section{Key Points}

Change-of-direction speed is a fundamental physical attribute in many field- and court-based team (e.g., soccer, handball, rugby) and individual sports (e.g., combat sports, tennis).

Resistance training appears to be an effective means to improve change-of-direction speed in youth and young physically active and athletic adults.

It seems that sex and age categories can moderate the effects of resistance training on change-of-direction speed with youth and males showing larger adaptive potential than adults and females.

Results from independently computed single factor analyses for different training variables revealed that higher compared with lower resistance training volumes, frequencies, and intensities appear not to have an advantage on the magnitude of training-induced improvements in change-of-direction speed.

\section{Introduction}

The ability to change direction while sprinting, also known as change-of-direction $(\mathrm{CoD})$ speed, is a fundamental physical attribute in many field-based team (e.g., soccer, handball, rugby) $[1,2]$ and individual (e.g., combat sports, tennis) sports [3-5]. Skilled change-of-direction movements represent an athlete's ability to decelerate as quickly as possible (i.e., braking phase) before rapidly re-accelerating (i.e., propulsive phase) in a new direction [1, 6]. Results from analyses of different sports have shown that $\mathrm{CoD}$ actions occur frequently (every 2-3 s) and repeatedly (> 1000/game) in soccer, tennis, rugby, and basketball [7]. Additionally, it has previously been demonstrated that CoD speed is effective in predicting on-field performance in American Football [8]. Further underlining its importance, $\mathrm{CoD}$ speed has been used to discriminate elite from sub-elite soccer players [2, 9-11], representing a practically relevant parameter for talent identification and selection [9, 11]. Accordingly, it is important to systematically develop CoD speed to increase sport performance and, ultimately, success in competition.
Several neural, biomechanical, anthropometric and musculoskeletal characteristics are associated with CoD speed $[1,6]$. Leg muscle quality, which is an umbrella term for reactive strength, concentric strength and power, eccentric strength, and left-right muscle imbalance appears to be an important predictor of $\mathrm{CoD}$ speed [6]. Generally, resistance training (RT) is an effective way to improve these muscle qualities in different populations across the lifespan and particularly in youth and young adult athletes $[12,13]$. This implies that RT-induced improvements in leg muscle quality may translate to CoD speed [14].

A number of published narrative reviews have reported testing-, training-, and performance-related issues associated with CoD speed [1, 2, 14]. For example, Brughelli et al. [14] summarised previous longitudinal studies that examined the effects of RT on CoD speed in recreationally active and athletic individuals. These authors reported no effect of strength and power training on $\mathrm{CoD}$ speed. However, it is noteworthy that most of the discussed protocols in the review of Brughelli et al. [14] lacked a control condition [15-18] making the inferences far from conclusive. In a systematic review with meta-analysis, Lesinski et al. [12] examined the effects of RT in young athletes on a wide range of measures of physical fitness, including CoD speed. These authors revealed that RT had moderate effects (standardised mean difference $[S M D]=0.68$ ) on CoD speed. However, they did not provide specific training-related recommendations on how to prescribe RT to enhance CoD speed. Moreover, findings were limited to youth athletes aged six to 18 years. Additionally, both Brughelli et al. [14] and Lesinski et al. [12] adopted a broad definition of RT and included heterogeneous intervention programmes that used complex and/or plyometric training. Indeed, the effects of the latter on $\mathrm{CoD}$ speed have previously been meta-analysed $[19,20]$. Specifically, Asadi et al. [20] demonstrated that plyometric training was effective in improving CoD speed (effect size $[E S]=0.96$ ) in physically active and athletic populations. Similarly, in another meta-analysis, Asadi et al. [19] showed that plyometric training improved CoD speed $(\mathrm{ES}=0.86)$ with a tendency towards greater training-related adaptations in more mature (mid [ES $=0.95]$ and postpubertal $[E S=0.99]$ ), compared with less mature (prepubertal [ES $=0.68]$ ), participants. Despite these findings, to date, no systematic review has examined the effects of RT (characterised by actions against external resistances [21, 22]) on CoD speed in youth and young physically active and athletic adults. 
Considering the above, the question of how to appropriately prescribe RT to optimise $\mathrm{CoD}$ speed needs to be further clarified so that coaches can build more focused programmes for their athletes. In an attempt to fill this gap in the literature, the first aim of this systematic review with meta-analysis was to characterise the effects of RT on CoD speed in healthy youth and young physically active and athletic adults. The second aim was to identify the main RT programme variables that could be used for training prescription.

\section{Methods}

This meta-analysis was conducted according to the preferred recording items for systematic review and meta-analyses (PRISMA) statements [23].

\subsection{Literature Search}

A systematic search was conducted in PubMed, Web of Science, and Google Scholar with no date restrictions up to October 2019. Only controlled trials, which were peerreviewed articles published in English, were considered. Keywords were collected through experts' opinion, literature review, and controlled vocabulary (e.g., Medical Subject Headings $[\mathrm{MeSH}])$. The following Boolean syntax was used: "resistance training"[Mesh] AND ("change of direction performance" OR "change of direction speed" OR agility) NOT (old OR elderly OR disease OR syndrome OR patient). Search results were screened by two researchers ( $\mathrm{HC}$ and $\mathrm{YN}$ ). In the process of selecting studies for inclusion, titles of all relevant articles were reviewed. Thereafter, abstracts and full texts were examined. Reference lists of review articles were manually searched for further potential studies that could be relevant for inclusion. An overview of the screening process is outlined in Fig. 1.

\subsection{Selection Criteria}

A PICOS (participants, intervention, comparators, study outcomes, and study design) approach was used to rate studies according to their eligibility [23]. The following inclusion criteria were defined a priori. (1) population: a cohort of healthy youth and/or young physically active/athletic (male and/or female) adults, aged 8-28 years (2) intervention: resistance training intervention programme. With reference to previous studies $[21,22]$, RT was defined as "[requiring] the musculature to contract against an opposing force generated by some type of external resistance" [that is not bodyweight] (3) comparators: active or passive control groups (4) outcomes: at least one measure of CoD speed (e.g., $T$ test time, Illinois CoD test time, 5-0-5 test time) with the performance outcome expressed in seconds (5) study design: controlled trials with baseline and follow-up measures. Exclusion criteria were defined a priori as follows: (1) a cohort with health problems (e.g., individuals with diabetes) (2) outside the predefined age range (3) RT programmes using body mass only (e.g., plyometric training) (4) RT programme combined with a non-external resistance (e.g., complex training) (5) no passive/active control group, and (6) lack of baseline and follow-up data in the study.

\subsection{Data Extraction}

Data extraction was performed by two reviewers (HC, YN) using a standardised form created in Microsoft Excel. The first reviewer collected data and the second verified study eligibility. In the case of no agreement regarding data extraction and study eligibility, UG was consulted for clarifications. To calculate effect sizes, baseline and follow-up means and standard deviations for the aforementioned outcome measures were used. Of note, given that time (s) was the main outcome measure, negative effect size values were used to represent improvements in performance. The characteristics of the included studies are displayed in Tables 1 and 2 .

\subsection{Study quality}

The risk of bias of the included studies was assessed using the Physiotherapy Evidence Database (PEDro) scale and the methodological quality of studies was rated on a scale from 0 (high risk of bias) to 10 (low risk of bias). A score of $\geq 6$ represented the threshold for studies with low risk of bias [24] (Table 3). Further, funnel plots were generated by plotting SMDs against the standard error of the SMD (seSMD) to visually inspect for asymmetry and to examine the risk of publication bias (i.e., systematic heterogeneity) [25]. In a symmetrical funnel plot, the effects of smaller studies should scatter widely at the bottom, with the spread narrowing amongst the larger studies [26] (Fig. 2).

\subsection{Results Analyses and Interpretation}

To examine the effectiveness of RT on CoD speed performance, between-subject standardised mean differences (SMDs) were computed as follows:

$\mathrm{SMD}=\frac{\text { Between }- \text { group mean outcome difference }}{\text { Pooled standard deviation of outcome among participants }}$.

To control for sample size, SMDs were adjusted according to the following equation $\left(1-\frac{3}{4 N-9}\right)$ [27] with $\mathrm{N}$ representing the total sample size. Quantitative data analysis was carried-out using RevMan version 5.3.5 [28]. A randomeffects model was used to weight each study and to 


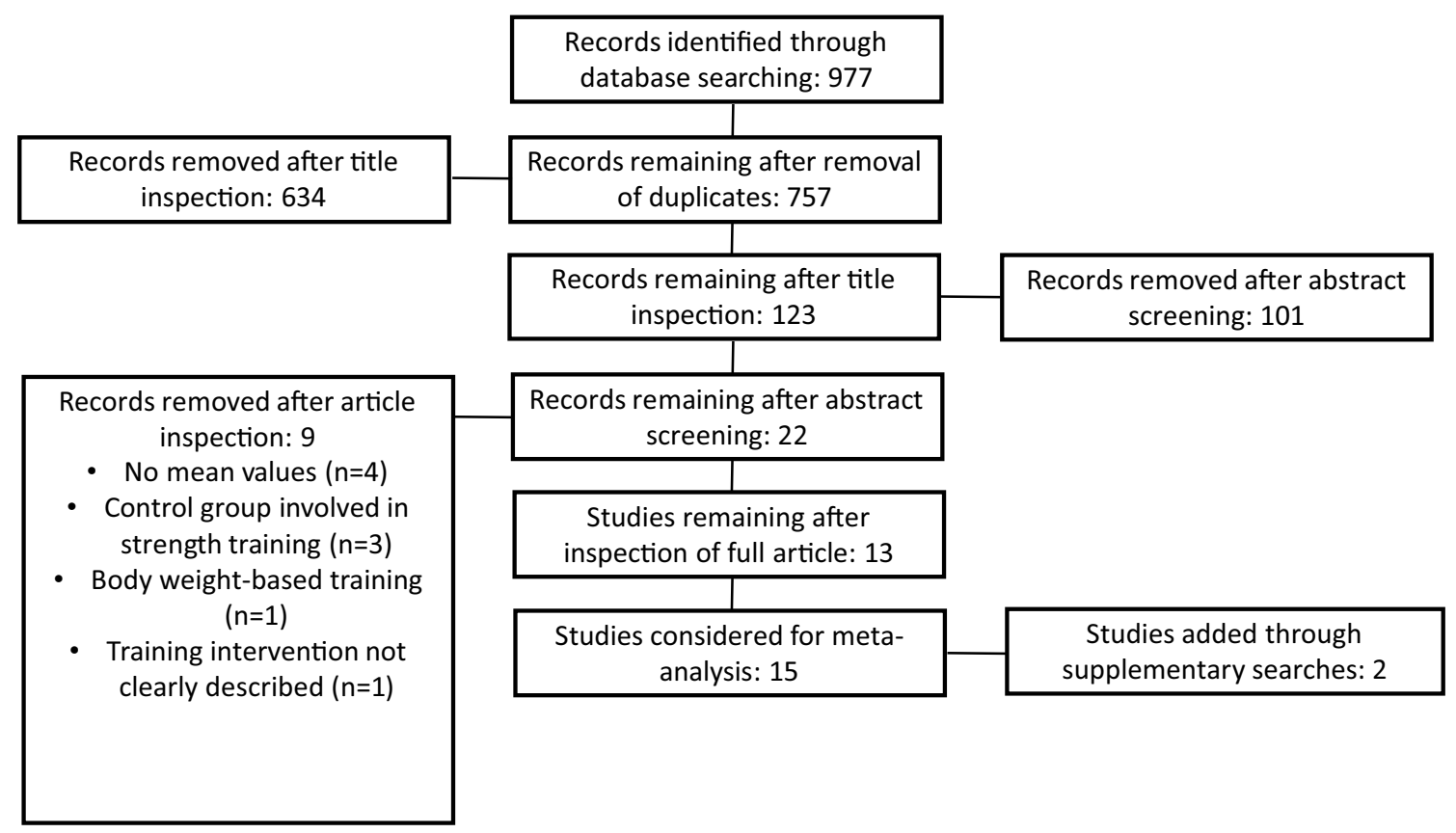

Fig. 1 Flow chart of the included and excluded studies

determine the SMDs which are presented alongside 95\% confidence intervals. The SMDs were interpreted using the conventions as outlined by Cohen [29] $(<0.2$ "trivial"; $\leq 0.2$ $\mathrm{SMD}<0.5$ "small", $\leq 0.5 \mathrm{SMD}<0.8$ "moderate", $\geq 0.8$ "large"). When more than a single intervention group was included in a study, the control group was proportionately divided to facilitate comparison amongst all participants [30]. In addition, a multivariate random effects meta-regression was conducted with Comprehensive Meta-analysis version 3.3.70 (Biostat Inc., Englewood, NJ, USA) to verify if any of the training variables predicted the effects of RT on CoD speed.

The level of between-study heterogeneity was assessed using the $I^{2}$ statistics. This indicates the proportion of effects that are caused by heterogeneity as opposed to chance [23]. Low, moderate, and high heterogeneity correspond to $I^{2}$ outcomes of 25,50 , and $75 \%$, respectively [31]. A value above $75 \%$ is rated as being considerably heterogeneous [32]. The $\chi^{2}$ (chi-square) statistic determines whether the differences in the results of the analysis are due to chance and in such a case, a low $p$ value, or high $\chi^{2}$ statistic, relative to degrees of freedom would be apparent [32]. The level of significance was set at $p<0.05$.

\subsection{Subgroup Analyses}

Age was considered a moderator variable and participants were classified as a youth (8-18 years) and young adults
(19-28 years). In the youth category, two sub-categories were considered: children (pre-pubertal, $\leq 13$ years) and adolescents (mid- and post-pubertal, $>13$ to $\leq 18$ years) [33]. This range was used due to previously established maturation-related adaptations following RT [34]. Sex was chosen as a moderator variable due to potential RT-related differences in adaptations between males and females [35, 36]. Training expertise was another moderator variable due to differences in the magnitude of RT-related adaptations between elite athletes and athletes of lower expertise [37, 38]. Athletes competing at the national and international levels were considered to be elite [39].

\subsection{Single Factor Analyses}

Single-factor analyses for training variables related to the applied RT programmes were conducted. For this purpose, we computed the effects of single training variables such as frequency (i.e., 2 vs. 3 sessions per week), session duration (i.e., $\leq 30 \mathrm{~min}$ vs. $\geq 45 \mathrm{~min}$ ), total training duration (i.e., $\leq 8$ vs. $>8$ weeks intervention), total number of training sessions (i.e., $\leq 16$ vs. $>16$ ), and training intensity [40] on RT-related adaptations in CoD speed. In terms of training intensity, RT intensities between 30 and $69 \%$ of the one-repetition maximum (1RM) were considered light-to-moderate [41]. RT intensities $\geq 70 \%$ of the $1 \mathrm{RM}$ were considered vigorousto-near maximal [41]. Training modality (i.e., free weights vs. machine-based training vs. combined free weights and 
Table 1 Characteristics of subjects from the included studies

\begin{tabular}{|c|c|c|c|c|c|c|c|c|}
\hline Study & Study group & Sex & Sport & Age (years) & $\begin{array}{l}\text { Body height } \\
(\mathrm{cm})\end{array}$ & $\begin{array}{l}\text { Body mass } \\
(\mathrm{kg})\end{array}$ & Participants & Training status \\
\hline \multirow[t]{2}{*}{$\begin{array}{l}\text { Hammami } \\
\text { et al. [48] }\end{array}$} & Exp & Male & Soccer & $16.2 \pm 0.6$ & $175 \pm 3$ & $58.0 \pm 6.2$ & 16 & $\begin{array}{l}\text { Experienced } \\
\text { level }\end{array}$ \\
\hline & Cont (active) & & & $16.8 \pm 0.2$ & $168 \pm 5$ & $58.1 \pm 5.2$ & 12 & \\
\hline \multirow{2}{*}{$\begin{array}{l}\text { Negra et al. } \\
{[47]^{\mathrm{a}}}\end{array}$} & Exp & Male & Soccer & $12.8 \pm 0.3$ & $159.3 \pm 8.4$ & $47.8 \pm 6.8$ & 12 & Regional level \\
\hline & Cont (active) & & & $12.7 \pm 0.3$ & $153.2 \pm 8.6$ & $42.5 \pm 5.5$ & 11 & \\
\hline \multirow{2}{*}{$\begin{array}{l}\text { Torres-Torrelo } \\
\text { et al. [63] }\end{array}$} & Exp & Male & Futsal & $23.8 \pm 2.4$ & $177.2 \pm 0.1$ & $73.6 \pm 7.0$ & 12 & Third division \\
\hline & Cont (active) & & & $24.7 \pm 4.7$ & $176.5 \pm 0.1$ & $75.9 \pm 7.1$ & 10 & \\
\hline \multirow[t]{3}{*}{$\begin{array}{l}\text { Prieske et al. } \\
\text { [45] }\end{array}$} & Exp 1 & $\begin{array}{l}\text { Male and } \\
\text { female }\end{array}$ & & $22.6 \pm 2.6$ & $176.6 \pm 8.7$ & $73.5 \pm 10.7$ & 10 & $\begin{array}{l}\text { Physically } \\
\text { active }\end{array}$ \\
\hline & Exp 2 & & & $23.4 \pm 3.2$ & $178.2 \pm 9$ & $72.2 \pm 9.6$ & 9 & \\
\hline & Cont (active) & & & $22.9 \pm 2.4$ & $174.9 \pm 8$ & $69.7 \pm 10.1$ & 16 & \\
\hline \multirow{2}{*}{$\begin{array}{l}\text { Negra et al. } \\
{[46]^{\mathrm{a}}}\end{array}$} & Exp & Male & Soccer & $12.8 \pm 0.2$ & $160.4 \pm 9.1$ & $49.2 \pm 8.1$ & 13 & Regional level \\
\hline & Cont (active) & & & $12.7 \pm 0.3$ & $154.5 \pm 11.1$ & $45.4 \pm 8.1$ & 11 & \\
\hline \multirow[t]{3}{*}{$\begin{array}{l}\text { Mcbride et al. } \\
\text { [44] }\end{array}$} & Exp 1 & Male & $\begin{array}{l}\text { Various activi- } \\
\text { ties }\end{array}$ & $24.2 \pm 1.8$ & $181.7 \pm 3.5$ & $84.4 \pm 4.6$ & 9 & Club level \\
\hline & Exp 2 & & & $21.6 \pm 0.8$ & $179.5 \pm 2.0$ & $80.5 \pm 3.8$ & 10 & \\
\hline & Cont (active) & & & $22.3 \pm 1.8$ & $176.5 \pm 3.0$ & $79.1 \pm 4.2$ & 7 & \\
\hline \multirow[t]{2}{*}{$\begin{array}{l}\text { Tricoli et al. } \\
\text { [64] }\end{array}$} & Exp & Male & $\begin{array}{l}\text { Various activi- } \\
\text { ties }\end{array}$ & $22.0 \pm 1.5$ & $179.4 \pm 8.8$ & $73.4 \pm 10.7$ & 12 & $\begin{array}{l}\text { Recreational } \\
\text { level }\end{array}$ \\
\hline & Cont (passive) & & & & & & 8 & \\
\hline \multirow[t]{2}{*}{$\begin{array}{l}\text { Christou et al. } \\
{[43]^{\mathrm{b}}}\end{array}$} & Exp & Male & soccer & $13.8 \pm 0.4$ & $162.0 \pm 3.8$ & $52.0 \pm 3.3$ & 9 & $\begin{array}{l}\text { Experienced } \\
\text { level }\end{array}$ \\
\hline & Cont (active) & & & $13.5 \pm 0.9$ & $163.0 \pm 2.5$ & $54.1 \pm 2.0$ & 9 & \\
\hline \multirow[t]{2}{*}{$\begin{array}{l}\text { Yildiz et al. } \\
\text { [65] }\end{array}$} & Exp 1 & Male & Tennis & $9.6 \pm 0.7$ & $134.1 \pm 6.8$ & $31.3 \pm 4.1$ & 10 & $\begin{array}{l}\text { Recreational } \\
\text { level }\end{array}$ \\
\hline & Cont (active) & & & & & & 8 & \\
\hline \multirow{2}{*}{$\begin{array}{l}\text { Whitehead } \\
\text { et al. [66] }\end{array}$} & Exp & Male & & $21.3 \pm 1.8$ & $177.3 \pm 9.4$ & $80.0 \pm 2.6$ & 10 & \\
\hline & Cont (passive) & & & & & & 10 & \\
\hline \multirow[t]{3}{*}{$\begin{array}{l}\text { Kraemer et al. } \\
\text { [67] }\end{array}$} & $\begin{array}{l}\text { Exp } 1 \text { (Perio- } \\
\text { dized) }\end{array}$ & Female & Tennis & $19.2 \pm 1.1$ & $167.9 \pm 5.6$ & $60.5 \pm 7.7$ & 9 & $\begin{array}{l}\text { Experienced } \\
\text { level }\end{array}$ \\
\hline & $\begin{array}{l}\text { Exp } 2 \text { (non- } \\
\text { periodized) }\end{array}$ & & & $18.6 \pm 1.3$ & $167.0 \pm 4.1$ & $60.8 \pm 7.8$ & 10 & \\
\hline & Cont (active) & & & $19.3 \pm 1.6$ & $167.3 \pm 6.1$ & $60.1 \pm 7.6$ & 8 & \\
\hline \multirow{2}{*}{$\begin{array}{l}\text { Hammami } \\
\text { et al. }[68]^{\mathrm{c}}\end{array}$} & Exp & Male & Soccer & $16.2 \pm 0.6$ & $175.0 \pm 3.0$ & $58.1 \pm 7.3$ & 19 & NR \\
\hline & Cont (active) & & & $15.8 \pm 0.2$ & $168.0 \pm 5.0$ & $58.2 \pm 5.0$ & 12 & \\
\hline \multirow[t]{4}{*}{$\begin{array}{l}\text { Deane et al. } \\
\text { [69] }\end{array}$} & Exp & Male & $\begin{array}{l}\text { Various activi- } \\
\text { ties }\end{array}$ & $21.2 \pm 3.9$ & $182.6 \pm 6.8$ & - & 13 & $\begin{array}{l}\text { Physically } \\
\text { active }\end{array}$ \\
\hline & & Female & & $22.2 \pm 3.9$ & $164.9 \pm 6.2$ & - & 11 & \\
\hline & Cont (passive) & Male & & $21.4 \pm 1.4$ & $181.7 \pm 6.8$ & - & 11 & \\
\hline & & Female & & $20.9 \pm 2.8$ & $164.5 \pm 8.4$ & - & 13 & \\
\hline \multirow{2}{*}{$\begin{array}{l}\text { Aloui et al. } \\
\text { [70] }\end{array}$} & Exp & Male & Soccer & $18.3 \pm 0.8$ & $184.0 \pm 5.0$ & $83.4 \pm 17.0$ & 15 & Elite level \\
\hline & Cont (active) & & & $18.8 \pm 0.8$ & $185.0 \pm 7.0$ & $78.7 \pm 13.8$ & 15 & \\
\hline \multirow[t]{2}{*}{$\begin{array}{l}\text { Barbalho et al. } \\
\text { [71] }\end{array}$} & Exp & Male & Soccer & $18.8 \pm 0.8$ & $178.4 \pm 6.2$ & $73.1 \pm 6.6$ & 12 & $\begin{array}{l}\text { Professional } \\
\text { level }\end{array}$ \\
\hline & Cont (active) & & & $19.1 \pm 0.9$ & $176.3 \pm 8.6$ & $72.0 \pm 5.9$ & 11 & \\
\hline
\end{tabular}

$N R$ not reported, Exp experimental group, Cont control group

${ }^{\text {a }}$ Prepubertal

${ }^{\mathrm{b}}$ Adolescent

${ }^{c}$ Pubertal 


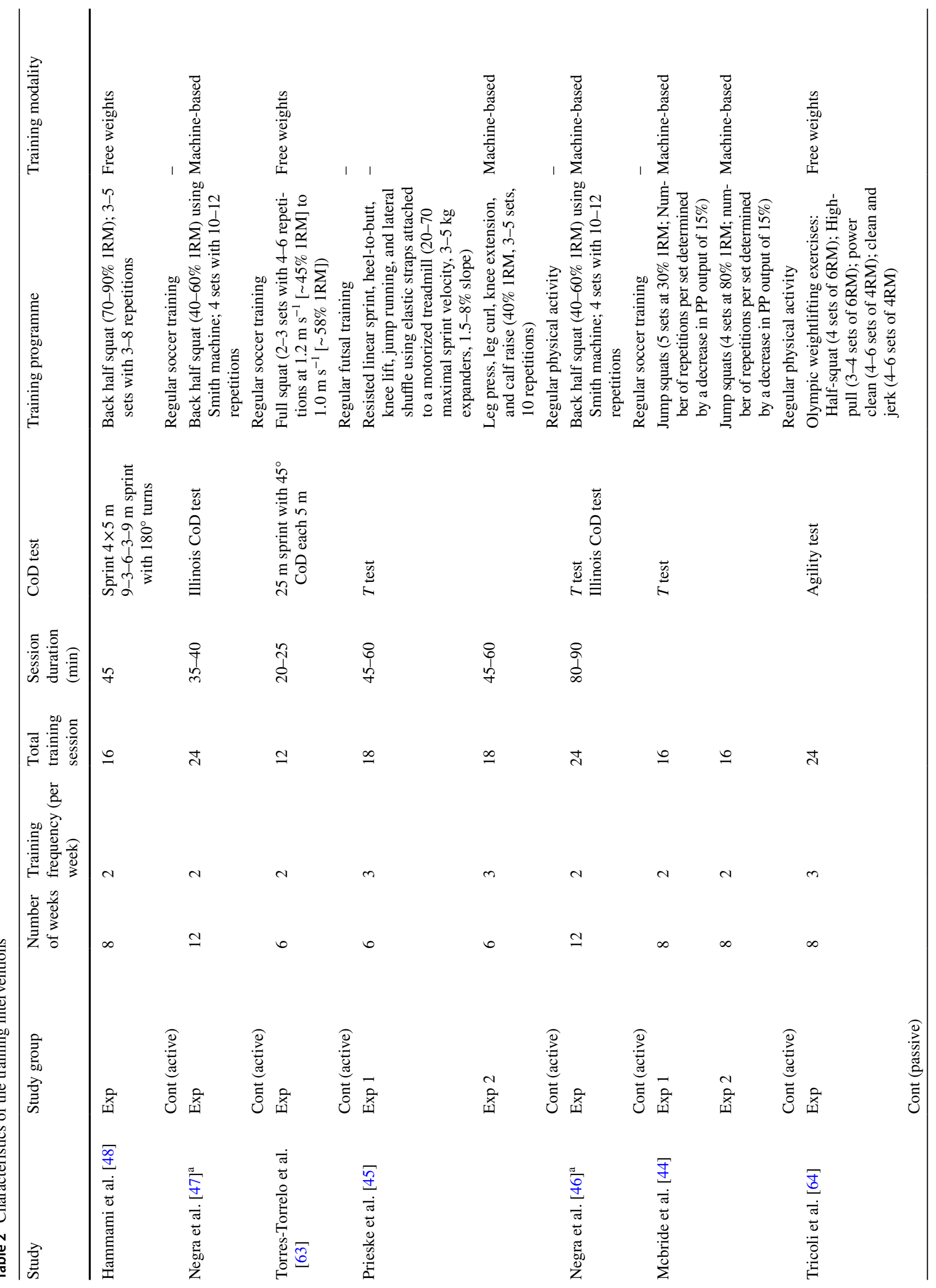




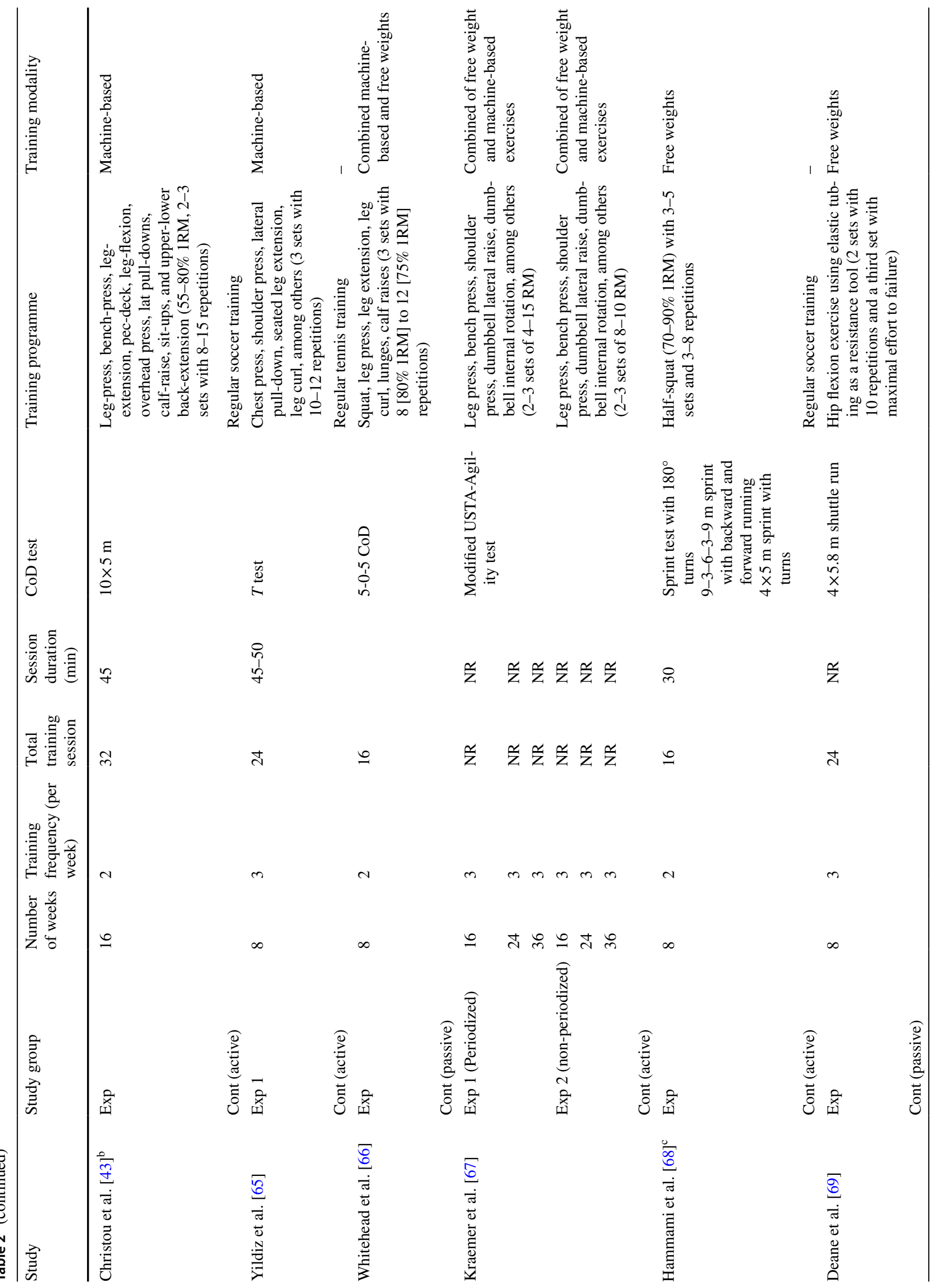




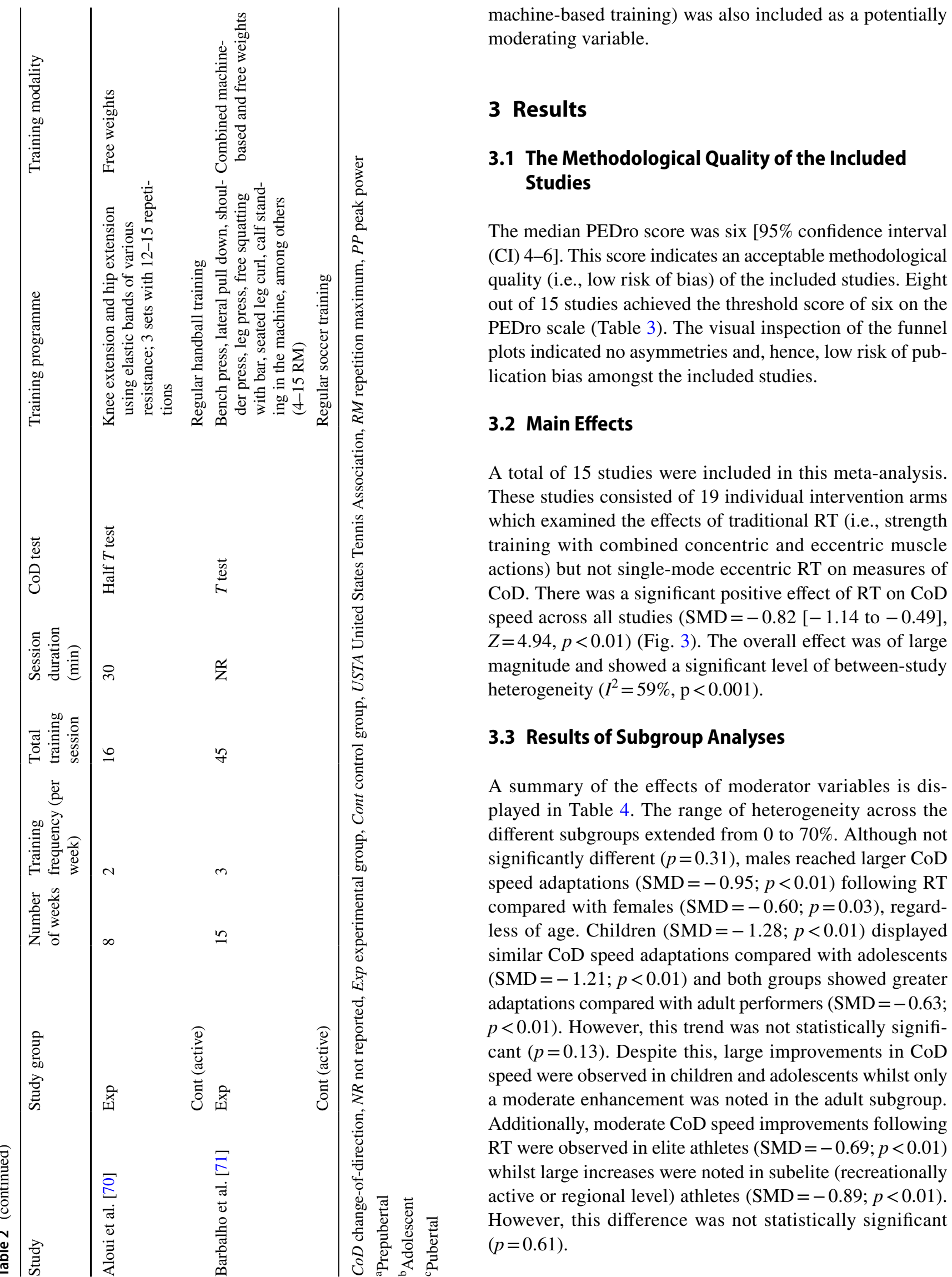




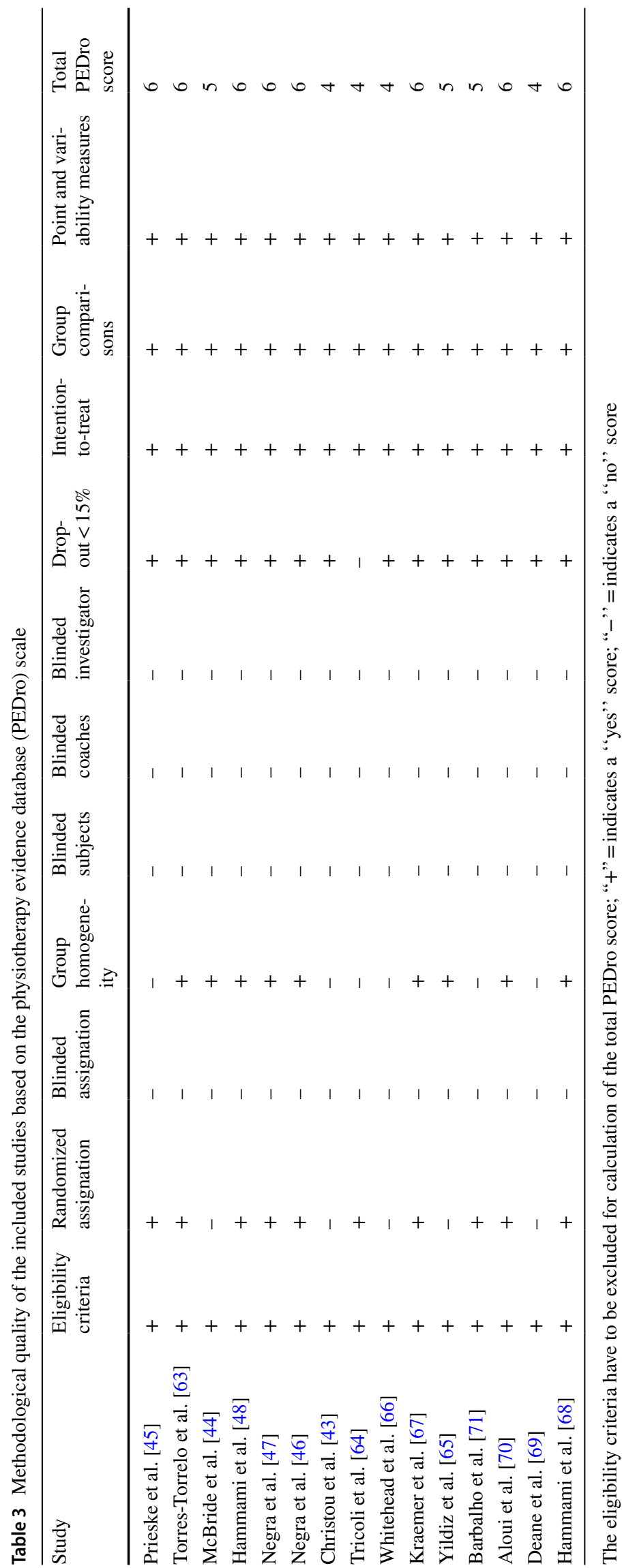




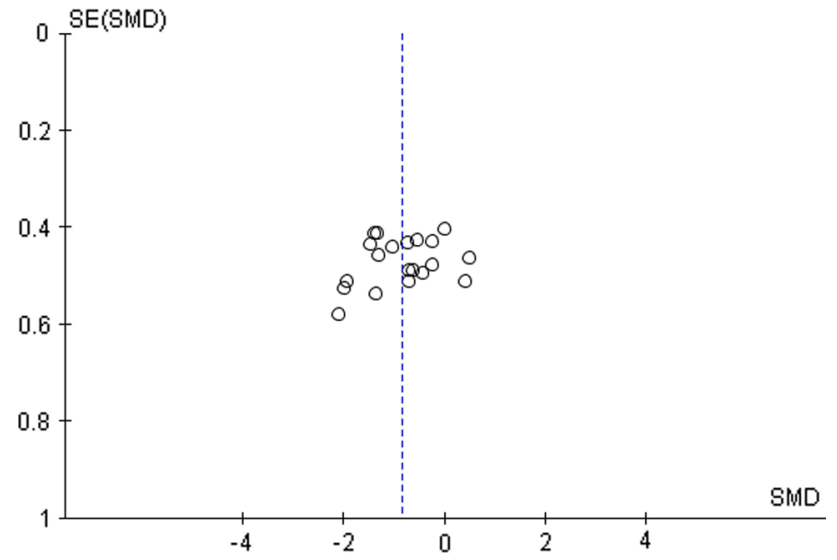

Fig. 2 Funnel plot illustrating the symmetrical distribution of the effects across the included studies. SMD standardised mean difference, $S E(S M D)$ standard error of the SMD

\subsection{Results of Single Training Factor Analyses}

Although not statistically significant $(p=0.09)$, RT interventions including two sessions per week induced larger CoD speed improvements $(\mathrm{SMD}=-1.07 ; p<0.01)$ than three sessions per week (SMD $=-0.54 ; p<0.05)$. Additionally, RT interventions that lasted $\leq 8$ weeks or $>8$ weeks induced similarly large effects on CoD speed $(\leq 8$ weeks: $\mathrm{SMD}=-0.81 ; p<0.01 ;>8$ weeks: $\mathrm{SMD}=-0.85$; $p<0.01)$ with no significant differences between subgroups $(p=0.91)$. Considering RT type, similar large effects following machine-based training $(\mathrm{SMD}=-0.80 ; p<0.01)$ and free weights training (SMD $=-0.99 ; p<0.01$ ) were observed on $\mathrm{CoD}$ speed. In terms of combined free weights and machine-based training, a moderate effect was noted $(\mathrm{SMD}=-0.77 ; p<0.05)$. The difference between the three training modalities was not statistically significant $(p=0.87)$. Furthermore, session durations of $\leq 30 \mathrm{~min}$ (SMD $=-1.00$; $p<0.01)$ or $\geq 45 \min (\mathrm{SMD}=-1.00 ; p<0.01)$ showed similarly large effects on CoD speed. Again, the difference between $\leq 30 \mathrm{~min}$ and $\geq 45$ min was not statistically significant $(p=0.99)$. In terms of the total number of training sessions, no significant differences were observed between $\leq 16$ or $>16$ sessions $(p=0.97)$. In both cases, the RT effect was of large magnitude $(\leq 16$ : SMD $=-0.83 ; p<0.01 ;>16$ : $\mathrm{SMD}=-0.81 ; p<0.01)$. Considering training intensity, light-to-moderate intensities $(\geq 30 \%$ to $<69 \% 1 \mathrm{RM})$ (SMD $=-0.76 ; p=0.05)$ were as effective as vigorous-tonear maximal $(\geq 70 \% 1 \mathrm{RM})(\mathrm{SMD}=-0.77 ; p<0.01)$ with no significant difference between the two ranges $(p=0.87)$.

\subsection{Results of the Meta-Regression}

The random effects meta-regression included four training variables (i.e., the total duration of the training, training frequency, training intensity, and session duration) (Table 5). None of the training variables significantly predicted the effects of RT on CoD speed ( $p=0.61-0.96)$. Additionally, the meta-regression analysis featured a coefficient of determination of $R^{2}=0.00$.

\section{Discussion}

CoD speed represents an important and practically relevant performance determinant in a wide range of team (e.g., soccer, handball, rugby, etc.) $[1,2]$ and individual (e.g., combat sports, tennis) sports [3-5]. Our findings revealed that RT is effective in improving CoD speed in youth and young physically active and athletic adults. In addition, these results demonstrate greater RT-related effects in males compared with females and in younger (i.e., children and adolescents) compared with older (i.e., adult) individuals. However, the observed differences between subgroups were not statistically significant. Independently computed single factor analyses for different training variables (i.e., frequency [2 vs. 3 sessions per week]; duration $[\leq 8$ vs. $>8$ weeks intervention]; session duration $[\leq 30 \mathrm{~min} v \mathrm{vs} . \geq 45 \mathrm{~min}]$; total number of RT sessions [ $\leq 16$ vs. $>16$ ]; and RT intensity [light-tomoderate vs. vigorous-to-near maximal]) and type (i.e., free weights vs. machine-based vs. combined free weights and machine-based training) indicated that there is no particular advantage of any single training variable or type over the other.

\subsection{Main Effects}

Several factors associated with leg muscle qualities (i.e., reactive strength, concentric/eccentric strength, and leftright muscle imbalance) have been suggested to be among the primary determinants of $\mathrm{CoD}$ speed [1, 42]. Chaabene et al. [6] previously indicated that to rapidly decelerate and accelerate the human body during CoD tasks, it is crucial to systematically develop eccentric (deceleration) and concentric (acceleration) strength of the lower limbs. The main finding of the present review indicated large positive effects of RT on CoD speed, regardless of sex, age, and training expertise. This suggests that the improvement of leg muscle qualities, particularly lower limb muscle strength, can transfer directly to CoD speed. This is in line with previously conducted controlled trials showing moderate-to-large effects of RT on CoD speed in young individuals [43-48]. For instance, Christou et al. [43] studied the effects of strength training on $\mathrm{CoD}$ speed in adolescent soccer players and observed performance improvements of approximately 3\% after 8 weeks and 5\% after 16 weeks of training. Likewise, Hammami et al. [48] examined the effects of RT on CoD speed in male soccer players aged 16 years 


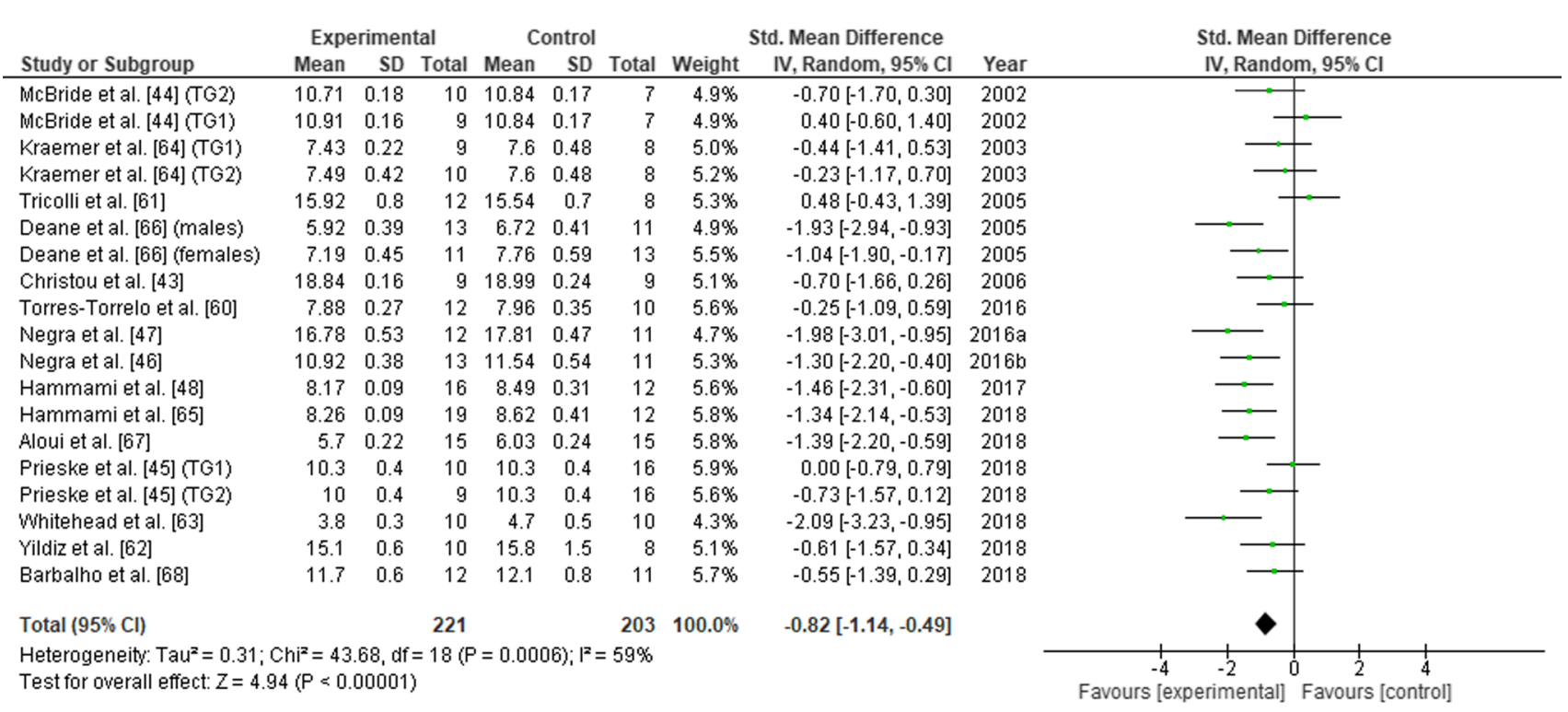

Fig. 3 Effects of resistance training (experimental) versus active/passive control on change-of-direction speed performance. $T G$ training group, $S D$ standard deviation, $C I$ confidence interval, $I V$ inverse variance

and demonstrated significant gains (2-4\%) after 8 weeks of training. Moreover, it has been shown that there are greater strength levels in individuals who are faster during $\mathrm{CoD}$ tests, compared with those who are slower [49, 50]. Overall, RT interventions that target lower limb muscle strength appear to be effective in enhancing CoD speed in youth and young physically active and athletic adults. The observed RT-related improvements in CoD speed could be caused by a combination of neural and morphological factors. In terms of neural factors, higher levels of motor unit recruitment and synchronization, as well as rate coding (firing frequency), may be among the main mechanisms that contribute to better $\mathrm{CoD}$ speed (39). These physiological mechanisms may enable more effective and efficient activation of the stretchshortening cycle [51]. Regarding morphological factors, an increase in the size of muscle fibres and, therefore, the level of force that a muscle and/or group of muscles can deliver, after RT could result in higher CoD speed performance [2]. It is well known that high levels of strength and power (rate of force development) are critical for performance in $\mathrm{CoD}$ speed tasks [13]. In light of this, RT has been shown to be effective in improving strength and power performances [12, $13,37]$ and, by extension, CoD speed.

\subsection{Subgroup Analyses}

Subgroup analyses indicated no significant sex differences with regards to the effects of RT on CoD speed. Regardless of this, it must be noted that the magnitude of the effect size was substantially larger in males ( $\mathrm{SMD}=-0.95$ ) than it was in females $(\mathrm{SMD}=-0.60)$. This aligns with the literature as it has been reported that males and females adapt differently to RT $[35,36]$. These difference in the level of adaptations could be caused by sex-related differences in circulating anabolic hormones $[52,53]$ which are elevated in males compared with females from puberty. Maturation-related changes in the hormonal system have an impact on muscle hypertrophy [53, 54]. For example, during the adolescent growth spurt, it has been demonstrated that males gain up to $7.2 \mathrm{~kg}$ of muscle mass per year while females gain $3.5 \mathrm{~kg}$ over the same time period [55]. Indeed, females experience a larger increase in fat mass (inactive tissue) than muscle mass (active tissue) during this key developmental period [56]. These maturational changes regulate adaptive responses to RT leading to lower training-related adaptations in females compared with males. Moran et al. conducted two metaanalyses dealing with the effects of RT on strength performance in young males [34] and females [40]. These authors revealed that males [34] achieved large strength adaptations following RT ( $\mathrm{SMD}=0.98$ ) while females displayed only moderate improvements $(\mathrm{SMD}=0.54)$ [40]. It is well-established that muscular strength represents an important performance determinant for $\mathrm{CoD}$ speed $[1,6]$. Accordingly, the observed greater training-related CoD speed improvements in males compared with females could partly be attributed to larger RT-related increases in muscle strength. Of note, there are fewer studies available that examined the effects of RT in females compared with males which is why we retrieved only three eligible studies that were conducted with females. This means that the outcome of the between-sex comparison must be interpreted with caution. Accordingly, 
Table 4 Subgroup and single training factor analyses

\begin{tabular}{|c|c|c|c|c|c|c|c|}
\hline Subgroup & Studies $(n)$ & Participants (n) & $\begin{array}{l}\text { Estimated effect size } \\
\text { Mean }(95 \%, \mathrm{CI})\end{array}$ & Within group $p$ & $\begin{array}{l}\text { Between } \\
\text { group } p\end{array}$ & $\begin{array}{l}\text { Within } \\
\text { group } I^{2} \\
(\%)\end{array}$ & Effect descriptor \\
\hline \multicolumn{8}{|l|}{ Sex } \\
\hline Male & 14 & 314 & $-0.95(-1.36$ to -0.53$)$ & $<0.01$ & \multirow[t]{2}{*}{0.31} & 64 & Large \\
\hline Female & 3 & 59 & $-0.60(-1.13$ to -0.07$)$ & 0.03 & & 0 & Moderate \\
\hline \multicolumn{8}{|l|}{ Age groups } \\
\hline Children $(\leq 13$ years $)$ & 3 & 65 & $-1.28(-2.02$ to -0.53$)$ & $<0.01$ & \multirow[t]{3}{*}{0.13} & 45 & Large \\
\hline $\begin{array}{l}\text { Adolescents }(>13 \\
\text { to } \leq 18 \text { years })\end{array}$ & 3 & 73 & $-1.21(-1.71$ to -0.71$)$ & $<0.01$ & & 0 & Large \\
\hline Young adults (19-28 years) & 13 & 282 & $-0.63(-1.04$ to -0.22$)$ & $<0.01$ & & 61 & Moderate \\
\hline \multicolumn{8}{|l|}{ Training experience } \\
\hline Elite & 4 & 88 & $-0.69(-1.21$ to -0.17$)$ & $<0.01$ & \multirow[t]{2}{*}{0.61} & 28 & Moderate \\
\hline $\begin{array}{l}\text { Recreational/active/regional } \\
\text { level }\end{array}$ & 15 & 336 & $-0.86(-1.26$ to -0.47$)$ & $<0.01$ & & 64 & Large \\
\hline \multicolumn{8}{|l|}{ Training frequency } \\
\hline 2 sessions/week & 10 & 229 & $-1.07(-1.52$ to -0.62$)$ & $<0.01$ & \multirow[t]{2}{*}{0.09} & 58 & Large \\
\hline 3 session/week & 9 & 195 & $-0.54(-0.97$ to -0.12$)$ & $\leq 0.01$ & & 50 & Moderate \\
\hline \multicolumn{8}{|l|}{ Training duration } \\
\hline$\leq 8$ weeks & 13 & 301 & $-0.81(-1.23$ to -0.38$)$ & $<0.01$ & \multirow[t]{2}{*}{0.91} & 66 & Large \\
\hline$>8$ weeks & 6 & 123 & $-0.85(-1.34$ to -0.35$)$ & $<0.01$ & & 41 & Large \\
\hline \multicolumn{8}{|l|}{ Training type } \\
\hline Machine-based training & 7 & 141 & $-0.80(-1.31$ to -0.29$)$ & $<0.01$ & \multirow[t]{3}{*}{0.87} & 50 & Large \\
\hline Free weights & 7 & 179 & $-0.99(-1.57$ to 0.40$)$ & $<0.01$ & & 69 & Large \\
\hline $\begin{array}{l}\text { Combined machine-based anc } \\
\text { free weights training }\end{array}$ & 4 & 78 & $-0.77(-1.51$ to -0.03$)$ & $<0.05$ & & 58 & Moderate \\
\hline \multicolumn{8}{|l|}{ Session duration } \\
\hline$\leq 30 \min$ & 3 & 83 & $-1.00(-1.72$ to -0.28$)$ & $<0.01$ & \multirow[t]{2}{*}{0.99} & 57 & Large \\
\hline$\geq 45 \min$ & 10 & 226 & $-1.03(-1.53$ to -0.47$)$ & $<0.01$ & & 69 & Large \\
\hline \multicolumn{8}{|l|}{ Total number of training sessions } \\
\hline \multirow[t]{2}{*}{$\leq 16$} & 9 & 215 & $-0.83(-1.32$ to -0.33$)$ & $<0.01$ & \multirow[t]{2}{*}{0.97} & 64 & Large \\
\hline & 610 & 209 & $-0.81(-1.27$ to -0.36$)$ & $<0.01$ & & 58 & Large \\
\hline \multicolumn{8}{|l|}{ Training intensity } \\
\hline$\geq 30$ to $<69 \% 1 \mathrm{RM}$ & 5 & 110 & $-0.76(-1.51$ to -0.01$)$ & $<0.01$ & \multirow[t]{2}{*}{0.87} & 70 & Moderate \\
\hline$\geq 70 \% 1 \mathrm{RM}$ & 9 & 192 & $-0.77(-1.24$ to -0.29$)$ & $<0.01$ & & 57 & Moderate \\
\hline
\end{tabular}

$C I$ confidence interval, $n$ number, $R M$ repetition maximum

Table 5 Outcomes of the multivariate random-effect meta-regression for training variables to predict RT effects on $\mathrm{CoD}$ speed performance in youth and young physically active and athletic adults

\begin{tabular}{lcllll}
\hline Training variables & Coefficient & Standard error & $95 \%$ CI & $Z$ value & Two-sided $p$-value \\
\hline Intercept & -1.5058 & 2.9525 & -7.29 to 4.28 & -0.51 & 0.6101 \\
Total duration of training & -0.0055 & 0.1246 & -0.25 to 0.24 & -0.04 & 0.9651 \\
Training frequency & 0.4208 & 1.1159 & -1.77 to 2.61 & 0.38 & 0.7061 \\
Session duration & -0.0084 & 0.022 & -0.05 to 0.03 & -0.38 & 0.7029 \\
Training intensity & -0.1203 & 0.7553 & -1.60 to 1.36 & -0.16 & 0.8735 \\
\hline
\end{tabular}

$R T$ resistance training, $C o D$ change-of-direction, $C I$ confidence interval future studies are warranted to examine the effects of RT on CoD speed in females.

Age was also considered a moderator because of previously established RT-related differences in adaptations between the various maturity stages [34]. Though chronological age is not directly aligned with maturation, older youth tend to be more mature than their younger counterparts [34]. Based on a previous study [33], participants 
were classified as children (pre-pubertal, $\leq 13$ years), adolescents (mid- and post-pubertal, $>13$ to $\leq 18$ years), and young adults ( $>18$ years). Our findings showed similar RT-related CoD speed improvements between children $(\mathrm{SMD}=-1.28)$ and adolescents $(\mathrm{SMD}=-1.21)$. However, when compared with adults $(\mathrm{SMD}=-0.63)$, children and adolescents achieved larger adaptations. Converse to this, Moran et al. [40] showed greater RT-related strength adaptations in older ( $>15$ years, $\mathrm{ES}=0.72$ ), compared to younger, $(<15$ years, $\mathrm{ES}=0.38)$ females. Likewise, in another metaanalysis examining the effects of RT on muscle strength in males, Moran et al. [34] demonstrated larger strength gains in pubertal $(\mathrm{ES}=1.11)$ and postpubertal $(\mathrm{ES}=1.01)$ compared with prepubertal individuals $(\mathrm{ES}=0.50)$. The authors attributed the lower magnitude of RT-related strength adaptations to the fewer pathways of adaptation in younger (i.e., mostly neural in nature) compared to older participants (i.e., neural and morphological factors) [34]. Asadi et al. [19] showed that plyometric training improved CoD speed $(\mathrm{ES}=0.86)$ with a tendency towards greater training-related adaptations in more mature (mid $[\mathrm{ES}=0.95]$ and postpubertal $[E S=0.99]$ ) compared with less mature (prepubertal $[E S=0.68]$ ) participants. The cause of this divergence between the outcomes of the present study and previous studies $[19,34,40]$ is not clear but it seems that other factors could have moderated the effects of RT on CoD speed. For instance, the main outcome differences between the present review (a task of relative strength and high coordinative level) and the previous research $[34,40]$ (task affording maximal strength) appear to have reversed the trend of adaptation. Moreover, categorising maturation was done in a slightly different way compared with previous studies [34, 40]. Specifically, the study of Moran et al. [34] does not include young adults category and considered mid and pubertal individuals in two separate categories. In the current study, the mid and pubertal subjects were merged into one single category. This could have affected the results. Also, the diminished resistance training-related adaptations observed in older compared with younger individuals can most likely be explained by the law of diminishing returns. Specifically, to achieve similar performance gains, individuals with high fitness status and/or more training experience (i.e., the time span an individual has been performing RT) have to increase their training volume more than individuals who are less fit and/or less experienced [57]. In fact, it has been shown that when the applied training stimulus is similar, individuals with more training experience are less likely to achieve large magnitudes of performance improvements compared with less experienced subjects $[37,56]$. This hypothesis is reinforced by the training status of the adult participants that were included in this meta-analysis. In fact, the training status ranged from physically active individuals to elite level athletes. Notably, the majority of participants were included in structured sports activities. We consider our maturity-specific findings preliminary given the limited studies that have been conducted with children $(n=3)$ and adolescents $(n=3)$, compared to adults $(n=13)$. Accordingly, more research is needed to examine the effects of RT on CoD speed adaptations according to biological maturity level. Additionally, given that the physiology of males and females varies with age and maturation [52, 58], further studies exploring sex-specific $\mathrm{CoD}$ speed adaptations following RT are needed, taking biological maturity into consideration.

In terms of the level of competitiveness of the participants, results demonstrated moderate CoD speed improvements to RT in elite athletes and large increases in sub-elite athletes. As outlined above, it has been reported that gains in any RT-related measure are affected by the degree of adaptation that has already been realised by a trainee [57, 59], implying the presence of a ceiling preventing continued adaptation. Indeed, a lower magnitude of adaptation would be expected in individuals with more, compared with less, training experience [56], explaining the larger RT-related adaptations in $\mathrm{CoD}$ speed in sub-elite compared with elite athletes.

\subsection{Effects of Single Training Factors}

Our findings showed larger RT-related $\mathrm{CoD}$ speed adaptation magnitude following two ( $\mathrm{SMD}=-1.07)$, compared with three, RT sessions per week $(\mathrm{SMD}=-0.54)$. However, this was not statistically significant. For the remaining variables (i.e., total training intervention duration and single session duration, number of training sessions, and training intensity), similar improvements were observed. Moran et al. [40] revealed larger RT-related adaptations in strength performance in studies with fewer training sessions $(\leq 16)$, shorter training intervention duration ( $\leq 8$ weeks) and lower training frequencies ( $\leq 2$ sessions per week) in females. Similar to what we observed, Asadi et al. [20] demonstrated no additional effects of high, compared to moderate, and low, intensity plyometric training on CoD speed. Overall, based on our findings, it seems more beneficial to favour lower over higher RT frequencies, volumes, and intensities to improve $\mathrm{CoD}$ speed in youth and young physically active and athletic adults. This may allow more time for sport-specific technical and tactical training and for the trainee to recover and adapt to the applied training stimuli [60]. Regarding RT type, our results indicate large-sized effects for free weights $(\mathrm{SMD}=-0.99)$ and machine-based training $(\mathrm{SMD}=-0.80)$ and moderate effects for combined free weights and machine-based training $(\mathrm{SMD}=-0.77)$. Of note, there were no significant differences between the three training modalities. Lesinski et al. [12] studied the effects of RT on components of physical fitness in young 
athletes. These authors revealed that RT interventions using free weights were more effective in improving muscle strength $(\mathrm{SMD}=2.97)$ and $\mathrm{CoD}$ speed $(\mathrm{SMD}=1.31)$ than other training modalities such as machine-based training and combined free weights and machine-based training. However, these findings are limited by the small number of studies that were included in each subanalysis. For example, for muscle strength, Lesinski and colleagues included three studies using machine-based RT and only two studies using RT with free weights [12]. For CoD speed, only one study used free weights RT and none used machine-based RT. Future research is needed that directly contrasts the effects of machine-based versus free weights RT on CoD speed. Eccentric RT has been shown to play a crucial role during CoD tasks, particularly during the braking (deceleration) phase [6]. However, we should mention that none of the included studies in this meta-analysis have examined the effects of eccentric RT. This raises a gap in the literature indicating that future studies are required to cover this promising topic.

\subsection{Limitations}

The present systematic review with meta-analysis has some limitations that warrant discussion. First, all the included studies examined the effects of RT on so-called 'pre-planned' CoD speed tests where no immediate reaction to a stimulus was required of the participant. Indeed, in an organic sports setting, directional changes are generally performed in response to an external stimulus (i.e. movement of opponent or ball) [1] and this means that in addition to the physical component of $\mathrm{CoD}$, a cognitive component (e.g., recognition of a stimulus, reaction) is also demanded. To the authors' knowledge, there are no studies available in the literature that examined the effects of RT on pure agility performance (i.e. physical and cognitive components) [2]. The few intervention studies available investigated the effects of small-sided games or video-based perceptual training on agility performance, among others [2]. This seems to be due to the complex nature of agility performance which is dependent on both the cognitive (decision making) and physical (e.g., acceleration/deceleration, etc) components of movement and performance [1]. Moreover, there appears to be a distinct lack of well-accepted and valid assessment protocols for agility as characterised by these observations. Of note, it has previously been postulated that the relevant importance of muscular strength may diminish if a cognitive challenge is included [2]. This is reinforced by a previous cross-sectional study showing trivial-to-small associations between agility and measures of physical fitness including muscle strength [50]. However, the question of the effects of RT on agility performance is yet to be explored and should be the focus of future studies. This could help to develop more ecologically valid training-related recommendations. A second limitation is related to the limited number of eligible studies and, particularly, the significant heterogeneity across the included studies which undermines the accuracy of the inter-study comparison. Moreover, for subgroup analyses, the dichotomisation of continuous data could result in residual confounding and reduced statistical power [61, 62].

\section{Conclusions}

RT seems to be an effective means to improve CoD speed in youth and young physically active and athletic adults. Regarding sex differences, our subgroup analyses showed that males achieved larger adaptations than females, though the differences were not statistically significant. Additionally, we noted greater RT-related CoD speed improvements in children and adolescents, compared with adults. This seems to be related to the lower training age in younger, compared to older participants which might negate other relevant factors such as fewer available pathways of adaptation. Furthermore, independently computed single factor analyses for different training variables showed that higher compared with lower RT volumes, frequencies, and intensities had no advantage in the magnitude of $\mathrm{CoD}$ speed improvements. This finding can be explained by the principle of training specificity and how it applies to the force-velocity relationship. In other words, high-speed movements as in CoD tasks afford strength exercises of low resistance and high movement speed. However, this hypothesis needs to be verified in future studies. Regarding RT type, comparable improvements in CoD speed were achieved following either free weights or machine-based training. This finding needs to be substantiated in future longitudinal studies.

Acknowledgements Open Access funding provided by Projekt DEAL. All authors met the authorship criteria for this journal and each author made a significant contribution to the final version of this paper. The authors would like to thank Jonas Höhne for his support with data extraction.

\section{Compliance with Ethical Standards}

Funding No sources of funding were used to assist in the preparation of this article.

Conflict of Interest Helmi Chaabene, Olaf Prieske, Jason Moran, Yassine Negra, Ahmed Attia and Urs Granacher declare that they have no conflicts of interest relevant to the content of this review.

Open Access This article is licensed under a Creative Commons Attribution 4.0 International License, which permits use, sharing, adaptation, distribution and reproduction in any medium or format, as long as you give appropriate credit to the original author(s) and the source, provide a link to the Creative Commons licence, and indicate if changes were made. The images or other third party material in this article are 
included in the article's Creative Commons licence, unless indicated otherwise in a credit line to the material. If material is not included in the article's Creative Commons licence and your intended use is not permitted by statutory regulation or exceeds the permitted use, you will need to obtain permission directly from the copyright holder. To view a copy of this licence, visit http://creativecommons.org/licenses/by/4.0/.

\section{References}

1. Sheppard JM, Young WB. Agility literature review: classifications, training and testing. J Sports Sci. 2006;24(9):919-32. https ://doi.org/10.1080/02640410500457109.

2. Paul DJ, Gabbett TJ, Nassis GP. Agility in team sports: testing, training and factors affecting performance. Sports Med. 2016;46(3):421-42. https://doi.org/10.1007/s40279-015-0428-2.

3. Chaabene H, Negra Y, Capranica L, Bouguezzi R, Hachana Y, Rouahi MA, et al. Validity and reliability of a new test of planned agility in elite taekwondo athletes. J Strength Cond Res. 2018;32(9):2542-7. https://doi.org/10.1519/jsc.000000000000232 5.

4. Young WB, Dawson B, Henry GJ. Agility and change-of-direction speed are independent skills: implications for training for agility in invasion sports. Int J Sports Sci Coach. 2015;10(1):159-69. https ://doi.org/10.1260/1747-9541.10.1.159.

5. Fernandez-Fernandez J, Ulbricht A, Ferrauti A. Fitness testing of tennis players: how valuable is it? Br J Sports Med. 2014;48(Suppl 1):i22-31. https://doi.org/10.1136/bjsports-2013-093152.

6. Chaabene H, Prieske O, Negra Y, Granacher U. Change of direction speed: toward a strength training approach with accentuated eccentric muscle actions. Sports Med. 2018;48(8):1773-9. https ://doi.org/10.1007/s40279-018-0907-3.

7. Stewart PF, Turner AN, Miller SC. Reliability, factorial validity, and interrelationships of five commonly used change of direction speed tests. Scand J Med Sci Sports. 2014;24(3):500-6. https:// doi.org/10.1111/sms.12019.

8. Davis DS, Barnette BJ, Kiger JT, Mirasola JJ, Young SM. Physical characteristics that predict functional performance in Division I college football players. J Strength Cond Res. 2004;18(1):11520. https://doi.org/10.1519/1533-4287(2004)018\%3c0115:pctpf $\mathrm{p} \% 3 \mathrm{e} 2.0 . \mathrm{co} ; 2$.

9. Reilly T, Williams AM, Nevill A, Franks A. A multidisciplinary approach to talent identification in soccer. J Sports Sci. 2000;18(9):695-702. https://doi.org/10.1080/026404100501200 78.

10. Hachana Y, Chaabene H, Ben Rajeb G, Khlifa R, Aouadi R, Chamari K, et al. Validity and reliability of new agility test among elite and subelite under 14-soccer players. PLoS One. 2014;9(4):e95773. https://doi.org/10.1371/journal.pone.0095773.

11. Unnithan V, White J, Georgiou A, Iga J, Drust B. Talent identification in youth soccer. J Sports Sci. 2012;30(15):1719-26. https:// doi.org/10.1080/02640414.2012.731515.

12. Lesinski M, Prieske O, Granacher U. Effects and dose-response relationships of resistance training on physical performance in youth athletes: a systematic review and meta-analysis. Br J Sports Med. 2016;50(13):781-95. https://doi.org/10.1136/bjsports-2015095497.

13. Suchomel TJ, Nimphius S, Stone MH. The importance of muscular strength in athletic performance. Sports Med. 2016;46(10):141949. https://doi.org/10.1007/s40279-016-0486-0.

14. Brughelli M, Cronin J, Levin G, Chaouachi A. Understanding change of direction ability in sport: a review of resistance training studies. Sports Med. 2008;38(12):1045-63. https://doi. org/10.2165/00007256-200838120-00007.
15. Fry AC, Kraemer WJ, Weseman CA, Conroy BP, Gordon SE, Hoffman JR, et al. The effects of an off-season strength and conditioning program on starters and non-starters in women's intercollegiate volleyball. J Strength Cond Res. 1991;5(4):174-81.

16. Cronin J, McNair PJ, Marshall RN. The effects of bungy weight training on muscle function and functional performance. J Sports Sci. 2003;21(1):59-71. https://doi.org/10.1080/026404103100007 1001.

17. Gabbett TJ. Skill-based conditioning games as an alternative to traditional conditioning for rugby league players. J Strength Cond Res. 2006;20(2):309-15. https://doi.org/10.1519/r-17655.1.

18. Harris GR, Stone MH, O'Bryant HS, Proulx CM, Johnson RL. Short-term performance effects of high power, high force, or combined weight-training methods. J Strength Cond Res. 2000;14(1):14-20.

19. Asadi A, Arazi H, Ramirez-Campillo R, Moran J, Izquierdo M. Influence of maturation stage on agility performance gains after plyometric training: A systematic review and meta-analysis. J Strength Cond Res. 2017;31(9):2609-17. https://doi.org/10.1519/ jsc.0000000000001994.

20. Asadi A, Arazi H, Young WB, Saez de Villarreal E. The Effects of plyometric training on change-of-direction ability: a metaanalysis. Int J Sports Physiol Perform. 2016;11(5):563-73. https ://doi.org/10.1123/ijspp.2015-0694.

21. Stone MH. Position statement: explosive exercise and training. Strength Cond J. 1993;15(3):7-15.

22. Siff $\mathrm{M}$. Biomechanical foundations of strength and power training. In: Zatsiorsky V, editor. Biomechanics in Sport. London: Blackwell Scientific Ltd; Wiley Online Library; 2001. p. 103-39.

23. Liberati A, Altman DG, Tetzlaff J, Mulrow C, Gotzsche PC, Ioannidis JP, et al. The PRISMA statement for reporting systematic reviews and meta-analyses of studies that evaluate health care interventions: explanation and elaboration. J Clin Epidemiol. 2009;62(10):e1-34. https://doi.org/10.1016/j.jclin epi.2009.06.006.

24. Maher CG, Sherrington C, Herbert RD, Moseley AM, Elkins M. Reliability of the PEDro scale for rating quality of randomized controlled trials. Phys Ther. 2003;83(8):713-21.

25. Sterne JA, Sutton AJ, Ioannidis JP, Terrin N, Jones DR, Lau J, et al. Recommendations for examining and interpreting funnel plot asymmetry in meta-analyses of randomised controlled trials. BMJ. 2011;343:d4002. https://doi.org/10.1136/bmj.d4002.

26. Begg CB, Berlin JA. Publication bias: a problem in interpreting medical data. J R Stat Soc Ser A (Statistics in Society). 1988;151(3):419-45.

27. Lv H, Olkin I. Statistical methods for meta-analysis. Orlando: Academic Press; 1985.

28. Review Manager version 5.3. Copenhagen: The Nordic Cochrane Centre, The Cochrane Collaboration. 2014.

29. Cohen J. Statistical power analysis for the behaviors science (2nd). New Jersey: Laurence Erlbaum Associates, Publishers, Hillsdale; 1988.

30. Higgins JP, Deeks JJ, Altman DG. Special topics in statistics. Cochrane handbook for systematic reviews of interventions: Cochrane book series. 2008. p. 481-529.

31. Higgins JP, Thompson SG, Deeks JJ, Altman DG. Measuring inconsistency in meta-analyses. BMJ. 2003;327(7414):557.

32. Deeks JJ, Higgins JP, Altman DG. Analysing data and undertaking meta-analyses. Cochrane handbook for systematic reviews of interventions: Cochrane book series. 2008. p. 243-96.

33. Rumpf MC, Cronin JB, Pinder SD, Oliver J, Hughes M. Effect of different training methods on running sprint times in male youth. Pediatric Exerc Sci. 2012;24(2):170-86. https://doi.org/10.1123/ pes.24.2.170.

34. Moran J, Sandercock GR, Ramirez-Campillo R, Meylan C, Collison J, Parry DA. A meta-analysis of maturation-related 
variation in adolescent boy athletes' adaptations to short-term resistance training. J Sports Sci. 2017;35(11):1041-51. https:// doi.org/10.1080/02640414.2016.1209306.

35. Yoshimoto T, Takai Y, Fukunaga Y, Fujita E, Yamamoto M, Kanehisa $\mathrm{H}$. Effects of school-based squat training in adolescent girls. J Sports Med Phys Fit. 2016;56(6):678-83.

36. Lloyd RS, Oliver JL. The youth physical development model: a new approach to long-term athletic development. Strength Cond J. 2012;34(3):61-72.

37. Suchomel TJ, Nimphius S, Bellon CR, Stone MH. The importance of muscular strength: training considerations. Sports Med. 2018;48(4):765-85. https://doi.org/10.1007/s40279-018-0862-z.

38. Kraemer WJ, Newton RU. Training for muscular power. Phys Med Rehabil Clin. 2000;11(2):341-68. https://doi.org/10.1016/s1047 -9651(18)30133-5.

39. Araújo C, Scharhag J. Athlete: a working definition for medical and health sciences research. Scand J Med Sci Sports. 2016;26(1):4-7. https://doi.org/10.1111/sms.12632.

40. Moran J, Sandercock G, Ramirez-Campillo R, Clark CCT, Fernandes JFT, Drury B. A meta-analysis of resistance training in female youth: its effect on muscular strength, and shortcomings in the literature. Sports Med. 2018;48(7):1661-71. https://doi. org/10.1007/s40279-018-0914-4.

41. Garber CE, Blissmer B, Deschenes MR, Franklin BA, Lamonte MJ, Lee IM, et al. American college of sports medicine position stand. Quantity and quality of exercise for developing and maintaining cardiorespiratory, musculoskeletal, and neuromotor fitness in apparently healthy adults: guidance for prescribing exercise. Med Sci Sports Exerc. 2011;43(7):1334-59. https://doi. org/10.1249/mss.0b013e318213fefb.

42. Chaabene $\mathrm{H}$. Change of direction tasks: does the eccentric muscle contraction really matter. Sci Pages Sports Med. 2017;1(1):1-2.

43. Christou M, Smilios I, Sotiropoulos K, Volaklis K, Pilianidis $\mathrm{T}$, Tokmakidis SP. Effects of resistance training on the physical capacities of adolescent soccer players. J Strength Cond Res. 2006;20(4):783-91. https://doi.org/10.1519/r-17254.1.

44. McBride JM, Triplett-McBride T, Davie A, Newton RU. The effect of heavy-vs. light-load jump squats on the development of strength, power, and speed. J Strength Cond Res. 2002;16(1):75-82.

45. Prieske O, Krüger T, Aehle M, Bauer E, Granacher U. Effects of resisted sprint training and traditional power training on sprint, jump, and balance performance in healthy young adults: a randomized controlled trial. Front Physiol. 2018;9:156. https://doi. org/10.3389/fphys.2018.00156.

46. Negra Y, Chaabene H, Hammami M, Hachana Y, Granacher U. Effects of high-velocity resistance training on athletic performance in prepuberal male soccer athletes. J Strength Cond Res. 2016;30(12):3290-7. https://doi.org/10.1519/jsc.0000000000 001433.

47. Negra Y, Chaabene H, Stögg1 T, Hammami M, Chelly MS, Hachana Y. Effectiveness and time-course adaptation of resistance training vs. plyometric training in prepubertal soccer players. J Sport Health Sci. 2016. https://doi.org/10.1016/j. jshs.2016.07.008.

48. Hammami M, Negra Y, Shephard RJ, Chelly MS. The effect of standard strength vs. contrast strength training on the development of sprint, agility, repeated change of direction, and jump in junior male soccer players. J Strength Cond Res. 2017;31(4):901-12. https://doi.org/10.1519/jsc.0000000000001815.

49. Spiteri T, Newton RU, Binetti M, Hart NH, Sheppard JM, Nimphius S. Mechanical determinants of faster change of direction and agility performance in female basketball athletes. J Strength Cond Res. 2015;29(8):2205-14. https://doi.org/10.1519/jsc.00000 00000000876
50. Young WB, Miller IR, Talpey SW. Physical qualities predict change-of-direction speed but not defensive agility in Australian rules football. J Strength Cond Res. 2015;29(1):206-12. https:// doi.org/10.1519/jsc.0000000000000614.

51. Komi PV. Stretch-shortening cycle. Strength and power in sport. Wiley Online Library. 2003;2:184-202.

52. McManus AM, Armstrong N. Physiology of elite young female athletes. The elite young athlete. Karger Publishers; 2011. p. 23-46.

53. Mauras N. Growth hormone and testosterone: effects on whole body metabolism and skeletal muscle in adolescence. Hormone Res Paediatrics. 2006;66(Suppl. 1):42-8.

54. Florini JR. Hormonal control of muscle growth. Muscle Nerve. 1987;10(7):577-98.

55. Tonnessen E, Svendsen IS, Olsen IC, Guttormsen A, Haugen T. Performance development in adolescent track and field athletes according to age, sex and sport discipline. PLoS One. 2015;10(6):e0129014. https://doi.org/10.1371/journal.pone.01290 14.

56. Faigenbaum A. Age- and sex-related differences and their implications for resistance exercise. Essentials of strength training and conditioning. Human Kinetics. National Strength \& Conditioning Association (US). 2000;3.

57. Rhea MR, Alvar BA, Burkett LN, Ball SD. A meta-analysis to determine the dose response for strength development. Med Sci Sports Exerc. 2003;35(3):456-64. https://doi.org/10.1249/01. Mss.0000053727.63505.D4.

58. Armstrong N, McManus AM. Physiology of elite young male athletes. The elite young athlete. Karger Publishers; 2011. p. 1-22.

59. Figueiredo VC, de Salles BF, Trajano GS. Volume for muscle hypertrophy and health outcomes: the most effective variable in resistance training. Sports Med. 2018;48(3):499-505. https://doi. org/10.1007/s40279-017-0793-0.

60. Zatsiorsky VM, Kraemer WJ. Science and practice of strength training. Human Kinetics; 2006.

61. Altman DG, Royston P. The cost of dichotomising continuous variables. BMJ. 2006;332(7549):1080.

62. Sandercock G, Bromley PD, Brodie DA. Effects of exercise on heart rate variability: inferences from meta-analysis. Med Sci Sports Exerc. 2005;37(3):433-9. https://doi.org/10.1249/01. mss.0000155388.39002.9d.

63. Torres-Torrelo J, Rodriguez-Rosell D, Gonzalez-Badillo JJ. Lightload maximal lifting velocity full squat training program improves important physical and skill characteristics in futsal players. J Sports Sci. 2017;35(10):967-75. https://doi.org/10.1080/02640 414.2016.1206663.

64. Tricoli V, Lamas L, Carnevale R, Ugrinowitsch C. Short-term effects on lower-body functional power development: weightlifting vs. vertical jump training programs. J Strength Cond Res. 2005;19(2):433-7. https://doi.org/10.1519/r-14083.1.

65. Yildiz S, Pinar S, Gelen E. Effects of 8-week functional vs. traditional training on athletic performance and functional movement on prepubertal tennis players. J Strength Cond Res. 2019;33(3):651-61. https://doi.org/10.1519/jsc.000000000000295 6.

66. Whitehead MT, Scheett TP, McGuigan MR, Martin AV. A comparison of the effects of short-term plyometric and resistance training on lower-body muscular performance. J Strength Cond Res. 2018;32(10):2743-9. https://doi.org/10.1519/jsc.0000000000 002083.

67. Kraemer WJ, Hakkinen K, Triplett-Mcbride NT, Fry AC, Koziris LP, Ratamess NA, et al. Physiological changes with periodized resistance training in women tennis players. Med Sci Sports Exerc. 2003;35(1):157-68. https://doi.org/10.1097/00005768200301000-00024. 
68. Hammami M, Negra Y, Billaut F, Hermassi S, Shephard RJ, Chelly MS. Effects of lower-limb strength training on agility, repeated sprinting with changes of direction, leg peak power, and neuromuscular adaptations of soccer players. J Strength Cond Res. 2018;32(1):37-47. https://doi.org/10.1519/jsc.000000000000181 3.

69. Deane RS, Chow JW, Tillman MD, Fournier KA. Effects of hip flexor training on sprint, shuttle run, and vertical jump performance. J Strength Cond Res. 2005;19(3):615-21. https://doi. org/10.1519/14974.1.

70. Aloui G, Hammami M, Fathloun M, Hermassi S, Gaamouri N, Shephard RJ, et al. Effects of an 8-week in-season elastic band training program on explosive muscle performance, change of direction, and repeated changes of direction in the lower limbs of junior male handball players. J Strength Cond Res. 2019;33(7):1804-15. https://doi.org/10.1519/jsc.0000000000 002786.

71. Barbalho M, Gentil P, Raiol R, Del Vecchio FB, RamirezCampillo R, Coswig VS. Non-linear resistance training program induced power and strength but not linear sprint velocity and agility gains in young soccer players. Sports. 2018. https://doi. org/10.3390/sports6020043.

\section{Affiliations}

\section{Helmi Chaabene ${ }^{1}\left(\mathbb{D} \cdot\right.$ Olaf Prieske $^{2}$ (D) $\cdot$ Jason Moran $^{3} \cdot$ Yassine Negra $^{4}\left(\mathbb{D} \cdot\right.$ Ahmed Attia $^{4} \cdot$ Urs Granacher $^{1}$ (D)}

\author{
Urs Granacher \\ urs.granacher@uni-potsdam.de \\ Helmi Chaabene \\ chaabanehelmi@hotmail.fr \\ Olaf Prieske \\ prieske@fhsmp.de \\ Jason Moran \\ jmorana@essex.ac.uk \\ Yassine Negra \\ yassinenegra@hotmail.fr \\ Ahmed Attia \\ ahmedattias@gmail.com
}

1 Division of Training and Movement Sciences, Research Focus Cognitive Sciences, University of Potsdam, Am Neuen Palais 10, Building 12, 14469 Potsdam, Germany

2 Division of Exercise and Movement, University of Applied Sciences for Sports and Management Potsdam, Potsdam, Germany

3 School of Sport, Rehabilitation and Exercise Sciences, University of Essex, Colchester, UK

4 Research Unit (UR17JS01) "Sport Performance, Health \& Society", Higher Institute of Sport and Physical Education of Ksar Said, University of "La Manouba", Tunis, Tunisia 